\title{
O brincar e as habilidades sociais na interação da criança com deficiência auditiva e mãe ouvinte
}

\author{
Playing and social skills in the interaction between \\ children with hearing impairments and hearing mothers
}

\author{
Angela Ferreira DOM INGUES 1 \\ Telma Flores Genaro MOTT12 \\ Maria Estela Guadagnucci PALAMIN ${ }^{3}$
}

\begin{abstract}
Resumo
Este artigo é resultado de um estudo que analisou a interação e o brincar entre 20 mães e seus filhos com deficiência auditiva, de graus severo e/ou profundo, com idades entre três e seis anos, em rotina de atendimento no Centro de Distúrbio da Audição, Linguagem e Visão do Hospital de Reabilitação de Anomalias Craniofaciais da Universidade de São Paulo. As mães foram entrevistadas e as respostas, analisadas quantitativa e qualitativamente. Os resultados mostraram que a interação com a mãe durante 0 brincar favorece o desenvolvimento de habilidades sociais para a adequação da criança ao seu meio social, e que as mães carecem de orientações, a fim de que esse espaço seja utilizado mais eficientemente para o aprendizado.

Unitermos: Brincar. Criança. Perda auditiva. Socialização.
\end{abstract}

\begin{abstract}
Thisarticleis theresult of a study assessing social interaction and playamong 20 mothersand theirchildren, between 3 and 6 yearsold, who suffer from a severe and/or profound hearing loss, in routinevisits to the Centro de Distúrbio da Audição, Linguagem e Visão, at the Hospital de Reabilitação de Anomalias Craniofaciais at the Universidade de São Paulo. Motherswereinterviewed and theirresponses were quantitatively and qualitatively assessed. Results showed that mother and child interaction during play assists with the development of social skills for adjusting to the social environment, and that mothers lack guidance, in order that this space is used more effectively for leaming purposes.

Uniterms: Recreation. Child. Hearing loss. Socialization.
\end{abstract}

A privação sensorial decorrente da deficiência auditiva, quando esta se dá na infância, pode interferir na aquisição de conhecimentos, particularmente na comunicação oral por parte da criança. Ao tomar a comunicação como fator primordial para o relacionamento entre indivíduos, pressupõe-se que a

\footnotetext{
1 Universidade de São Paulo, Hospital de Reabilitação de Anomalias Craniofaciais, Especialização em Psicologia Clínica. Bauru, SP, Brasil.

2 Universidade de São Paulo, Centro de Distúrbios da Audição, Linguagem e Visão, Hospital de Reabilitação de Anomalias Craniofaciais. R. Benedito Moreira Pinto, 8-81, Jardim Panorama, 17011-110, Bauru, SP, Brasil.Correspondência para/Correspondence to:T.F.G. MOTTI. E-mail: <telmotti@centrinho.usp.br>.

3 Universidade de São Paulo, Centro de Distúrbios da Audição, Linguagem e Visão, Hospital de Reabilitação de Anomalias Craniofaciais, Setor de Psicologia. Bauru, SP, Brasil.
} 
interação de uma criança com deficiência auditiva e seu meio social seja dotada de especificidades.

o princípio norteador deste estudo foi que grande parte dos conhecimentos é adquirida na interação do sujeito com o meio social. Para efeito de análise, fixou-se no desenvolvimento das habilidades sociais da criança com deficiência auditiva em sua interação com a mãe. A proximidade da mãe com a criança favorece a aprendizagem de comportamentos sociais adequados, em especial, nas atividades de brincar.

A consideração sobre o comportamento da criança deve se basear no contexto em que ela vive. Ao avaliá-lo como inadequado, segundo Marinho (2001), deve-se procurar seus determinantes no padrão de interação entre os membros da família, lembrando que a maioria dos comportamentos esperados é aprendida.

\section{A deficiência auditiva e suas implicações na criança}

A deficiência auditiva pode ser classificada, de acordo com Santos e Russo (1993), em função do momento em que ocorre, origem, local onde está instalada e grau (leve, moderado, severo e profundo). No momento de sua ocorrência, deve ser identificado se a deficiência auditiva é congênita, ou seja, se a alteração da função auditiva estava presente no momento do nascimento, ou se a deficiência auditiva manifestou-se tardiamente, após o nascimento.

Para este estudo, elegeu-se como tema a deficiência auditiva de graus severo e profundo, independente daépoca de manifestação, por serem osgraus que provocam maior dificuldade no desenvolvimento da comunicação entre 0 indivíduo e seu meio.

Goldfeld (1997) destaca o fato de que as crianças surdas não adquirem a língua oral em ritmo semelhante ao das crianças ouvintes, ou seja, a aquisição da linguagem é lenta e insuficiente para um bom desenvolvimento. Silva (2002) completa essa afirmação propondo que a dificuldade do sujeito em apropriar-se da língua oral gera obstáculos para sua inserção na cultura, uma vez que a palavra é o instrumento fundamental para o desenvolvimento das funções superiores.

Quanto à atividade verbal, Peña (1992) destaca que esta se dá fundamentalmente na interação com outras pessoas. Somam-se a isso as afirmações de Del Rio e Vilasseca (1992), apud Goldfeld (2000), de que a avaliação da linguagem deve englobar também aspectos funcionais. Segundo os autores, o desenvolvimento da linguagem depende de uma relação adequada e efetiva com 0 ambiente com o qual a criança interage, além dos aspectos maturacionais. A relação da criança com 0 ambiente proporciona o desenvolvimento de certas habilidades, além da linguagem, que facilitarão a interação com outras pessoas.

Juarez (1992) diz que um trabalho precoce e intensivo permite que a criança com surdez severa seja capaz de desenvolver voz e articulação inteligíveis que, unidas à leitura labial, Ihe proporcionem uma compreensão relativamente satisfatória, quando há boas condições de comunicação. Quanto à surdez profunda, a compreensão verbal depende da leitura labial, sendo a aquisição da linguagem oral particularmente difícil.

Ao acompanhar 50 famílias de crianças deficientes auditivas, menores de sete anos, que haviam sido atendidas por uma equipe interdisciplinar, Motti (2000) verificou que os pais estavam lidando melhor com o filho e seguiam as orientações recebidas, relatando melhora na comunicação e redução dos problemas de comportamento, atuando eles próprios com as crianças, já que não dispunham de recursos para custear os atendimentos recomendados pelos profissionais, sugerindo a autora um maior investimento nos pais.

Villas Boas, Rodrigues e Yamada (2004) analisaram uma criança de cinco anos de idade com perda auditiva profunda, que recebeu implante coclear, com o objetivo de comparar os comportamentos da mãe, antes e após intervenção sistemática em situação do cotidiano e de brinquedo livre, uma vez que o sucesso da reabilitação com esse dispositivo não depende apenas do seu uso, mas de como está organizado o ambiente da criança que o utiliza. Com a intervenção, as autoras verificaram que foi possível não só prover orientações à mãe, mas esclarecer dúvidas quanto aos comportamentos da filha, e concluíram que houve favorecimento de mudanças nas atitudes maternas que se refletiram no comportamento da criança, promovendo maior interação entre ambas.

Janjua, Woll e Kyle (2002) estudaram a interação entre pais e filhos em 13 crianças com perda auditiva 
severa e/ ou profunda, com menos de três anos de idade. A investigação focou a análise de possibilidades e leitura de livros, selecionando períodos de três minutos das sessões gravadas em vídeo, durante um ano, e com intervalos de três meses. Concluíram que o desenvolvimento da linguagem parece ser facilitado se for encorajada a participação e interação centrada na criança, por meio de jogos e conversas.

A interação com o meio social, se favorável em termos psicossociais, possibilita um desenvolvimento mais adequado. A interação dos pais com as crianças, porpertencerem a um círculo de relações mais próximo, favorece experiências importantes na aquisição da linguagem e no desenvolvimento psicossocial.

\section{Habilidades sociais}

Habilidades sociais são consideradas fatores aprendidos para a emissão de comportamentos adequados, diante das diversas situações do cotidiano.

Del Prette e Del Prette (1999) informam que o termo habilidade social refere-se ao desempenho do indivíduo em interações sociais, e pode ser classificado dentro de três dimensões: pessoal, situacional e cultural. A dimensão pessoal divide as habilidades sociais em duas classes de comportamentos: molares (capacidade para fazer pedidos, iniciar, manter e encerrar conversas, expressar afeto, dentre outras) e moleculares (componentes verbais de conteúdo e forma, não verbais, cognitivo-afetivos e fisiológicos).

Segundo Del Prette e Del Prette (1999), o desenvolvimento das habilidades sociais é multideterminado. Estes autores propõem modelos explicativos que permitem compreender as habilidades sociais, por exemplo, quanto à percepção ou expressão das mesmas pelos indivíduos, e dividem em cinco categorias as principais características necessárias para a análise de um quadro adequado de habilidades sociais que integram os comportamentos do indivíduo: a) assertividade (ansiedade interpessoal, que resulta no desempenho social adequado); b) percepção social (compreensão do contexto, selecionando o comportamento mais adequado e destacando uma discriminação de como deve ser o próprio comportamento, e se este ocorre ou não em determinada situação); c) aprendizagem social (habilidades sociais aprendidas a partir das experiências interpessoais, da observação e assimilação do desempenho do outro, como modelo para aquisição do seu repertório social); d) cognitivo (mediado por habilidades sócio-cognitivas, aprendidas pelo sujeito na interação com o seu meio, coordenando pensamento e ação, para atender aos objetivos previamente aceitos socialmente); e) teoria de papéis (conhecimento de si mesmo e do outro, com elementos simbólicos, verbais ou não verbais a eles associados).

Relação mãe e filho e o brincar

Goldfeld (2000) observa que, ao dar significado às ações e sons do filho, a mãe propicia a formação de conceitos pela criança e, por representar a sociedade para a criança, estabelece um importante elo entre ela e o mundo. Para Calderon e Greenberg (1999), as habilidades maternas de resolução de problemas estão diretamente ligadas ao ajuste e aprendizagem da criança.

MacDonald e Pien (1982) pesquisaram, em 12 díades de mães e crianças menores de cinco anos, sem doenças, o modo peculiar de a mãe se dirigir à criança, etambém as características da fala matema, que podem refletir em diferentes efeitos sobre $o$ desenvolvimento da mesma. Investigaram formas de brincar em um ambiente lúdico, e concluíram que a prevalência de questionamentos e frases imperativas, e a escassez de declarações, parecem inadequadas paraa comunicação mãe-criança.

Moyles (2002) afirma que, em todas as idades, 0 brincar é realizado por puro prazer e diversão, criando no sujeito uma atitude alegre em relação à vida e à ap rendizagem. Para a autora, a estimulação, a variedade, o interesse pela atividade, a concentração e a motivação podem ser proporcionados por atividades lúdicas.

Poletto (2005) investigou como o lúdico aparece no contexto diário da vida de 40 crianças, entre sete e dez anos de idade, em situação de pobreza econômica. Desenvolveu seu estudo por meio de entrevistas, brinquedos, brincadeiras, dando-lhes tempo e espaço para brincar, e verificando quais as companhias preferidas pelas crianças, bem como a visão de seus familiares. Constatou que os familiares/cuidadores compreendem a necessidade das crianças de brincare propiciam tempo, espaço e companhia para as 
brincadeiras, quando solicitado e possível. Em grande parte, os pais conseguem ter prazer nas atividades lúdicas realizadas com os filhos, utilizando jogos e conversas. Sugeniu também programas que beneficiem as interações entre os familiares/cuidadores e as crianças, a fim de que o lúdico possa servir como instrumento de mediação nas diversas relações.

Desta forma, o brincar pode ser considerado fonte de aprendizagem de regras sociais. Para os pais, além de proporcionar oportunidade de conhecer as potencialidades e limites da sua criança, ao se depararem com o real estágio de desenvolvimento da mesma, podem adequar sua atuação, favorecendo o processo de desenvolvimento.

Já a criança, com base em ações sobre os objetos que usa para brincar, passa a ter consciência dos mesmos, a se relacionar ativamente com eles e a imitar situações do mundo adulto, criando um mundo de faz-de-conta, como norteador das suas experiências. As situações abstratas de mundo que ela cria proporcionam um meio para o desenvolvimento do pensamento e a constituição dos comportamentos.

Como brincaré a atividade básica para todas as crianças e pode ser explorado no sentido educativo, quando se pensa na criança surda, Silva (2002) explica que o brincar assume a finalidade de possibilitar a compreensão e interpretação de uma cultura marcada pela oralidade.

0 brincar é, portanto, uma rica atividade, que pode ser explorada, proporcionando meios de desenvolvimento das habilidades sociais para as crianças de maneira geral. Paralelamente, a motivação da criança é guiada justamente pelo interesse e necessidade de apropriar-se de um universo do qual ela quer fazer parte: 0 universo do adulto. Esse universo requer habilidades que ela precisa desenvolver para adequar-se ao meio social, obtendo sucesso em sua trajetória.

O objetivo deste trabalho foi analisar a interação mãe ouvinte e criança com deficiência auditiva severa e/ou profunda, durante o brincar, enquanto atividade facilitadora, para o desenvolvimento das habilidades sociais da criança.

\section{Método}

O projeto de pesquisa foi aprovado pelo Comitê 40 de Ética em Pesquisa, do Hospital de Reabilitação de
Anomalias Craniofaciais (HRAC) da Universidade de São Paulo (USP).

O estudo foi desenvolvido dentro de uma perspectiva quantitativa e qualitativa, no Centro de Distúrbios da Audição, Linguagem e Visão (CEDALVI), do HRAC/USP, em Bauru (SP), que oferece serviço interdisciplinar aos portadores de deficiência auditiva. Esse serviço caracteriza-se por atendimentos especializados, diagnósticos e/ou adaptação de aparelho de amplificação sonora individual (AASI) (Motti, 2000).

\section{Participantes}

Participaram do estudo 20 mães de crianças com idades entre três e seis anos, portadoras de deficiência auditiva severa e/ou profunda previamente diagnosticada, e que se encontravam em rotina de atendimento no CEDALVI. As mães apresentavam idades entre $21 \mathrm{e}$ 50 anos, sendo $45 \%$ delas dona de casa/do lar. Quanto à escolaridade, $20 \%$ das mães tinham terceiro grau completo, $35 \%$ segundo grau completo, $40 \%$ primeiro grau completo, das quais $20 \%$ haviam iniciado 0 segundo grau, e $5 \%$ tinham o primeiro grau incompleto. Quanto à origem, todas as famílias do estudo residiam em zona urbana, nos estados de São Paulo (35\%), Minas Gerais (30\%) e demais localidades do país, como Distrito Federal, Goiás, Alagoas e Mato Grosso.

Instrumentos

O instrumento utilizado para a coleta dos dados foi uma entrevista, elaborada com questões abertas e fechadas, visando levantar informações sobre aspectos facilitadores e não facilitadores para o desenvolvimento das "habilidades sociais" em crianças com deficiência auditiva. As questões abordavam o tempo que a mãe dedicava à criança no dia-a-dia, entre cuidados, brincadeiras e estimulação, e o tempo que a criança passava junto a outras crianças; se ela preferia brincar sozinha ou acompanhada; como a mãe considerava o relacionamento da criança com os demais; como era 0 relacionamento em casa; se a criança recorria mais ao pai ou à mãe; quais as dificuldades encontradas pela mãe ao brincar com a criança; se a mãe corrigia e como corrigia seus comportamentos; e se ela era capaz de fazer pedidos e de realizar pequenas atividades em casa.

2008 
Procedimentos

As entrevistas foram realizadas no CEDALVI, em sala de atendimento individual do setor de Psicologia. Após a interpretação do estudo para as mães das crianças com deficiência auditiva que se encontravam em atendimento, da entrega da Carta de Informação ao Sujeito da Pesquisa e da assinatura do Termo de Consentimento Livre e Esclarecido, as entrevistas foram realizadas, gravadas e transcritas, procedendo-se à análise das respostas, conforme o objetivo do estudo.

\section{Resultados e Discussão}

0 aspecto inicialmente analisado foi o tempo que a mãe passava junto à sua criança deficiente auditiva. As respostas mostraram que $15 \%$ delas passavam o dia todo, 35\% passavam dois períodos por dia (por exemplo, manhã e noite), $25 \%$ passavam um período do dia (cerca de quatro horas) e $25 \%$ passavam de uma a três horas. Outros familiares ficavam com a criança, em $40 \%$ dos casos, cerca de um período por dia, 35\% o dia todo e $25 \%$ das crianças ficavam só com a mãe ou "um pouco" (menos de três horas) com outro familiar.

Observou-se que as mães participantes deste estudo procuravam estar com seus filhos todo o tempo disponível, enquanto eles não estavam na escola, sendo que apenas $15 \%$ delas tinham total disponibilidade para acompanhar as crianças nos cuidados e nas atividades de estimulação do desenvolvimento e acompanhamento escolar. Assim, estando presentes na maior parte do tempo com o filho, é possível, para as mães, perceberem suas dificuldades no que diz respeito ao convívio social, e orientá-los com mais eficiência, favorecendo o que Gomide (2001) defende como monitoria freqüente: um poderoso inibidor de condutas anti-sociais, conduzindo à aprendizagem dos comportamentos socialmente aceitos e extinguindo os inadequados.

É nesse sentido que Poletto (2005) verificou, em seu estudo, que osfamiliares/cuidadorescompreendem e favorecem o brincar para as crianças, quando possível. No entanto, as mães podem se beneficiar de orientação profissional para melhor aproveitamento desses momentos, de acordo com Motti (2000) e Villas Boas et al. (2004), que identificaram a possibilidade de esclarecimento de dúvidas, com reflexos no comportamento da criança.

Motti (2000) e Poletto (2005) também sugerem programas que promovam interações entre os familiares/cuidadores e as crianças nos diversos ambientes, com a utilização do lúdico como instrumento de interação.

O contato da criança com outras da mesma faixa etária foi afirmativo em $100 \%$ das respostas, na família ou na escola, situação fundamental para um bom desenvolvimento social. O contato com outras pessoas, em especial com crianças, facilita o enfrentamento da crítica e a recepção de estimulação adequada, sendo o "brincar com parceiro"um exercício de interação social, por meio do qual a criança aprende a respeitar regrase cumprir normas; mas Cunha (1994) também destaca que brincar sozinho é importante, pois possibilita à criança exercitar sua capacidade de concentrar a atenção em uma atividade e lidar com a afetividade.

Neste estudo, identificou-se que 50\% das crianças têm o hábito de brincar acompanhadas de irmãos ou primos, e $50 \%$, de brincar sozinhas; mas, mesmo estas, costumam ter companhia de familiares e/ou amigos. Assim, o treino das principais categorias apontadas por Del Prette e Del Prette (1999) para um bom desenvolvimento das habilidades sociais, como: assertividade, teoria de papéis, percepção e aprendizagem social, está assegurado para as crianças analisadas. E tratar a brincadeira como atividade social específica é fundamental como garantia de interação social e da elaboração de conhecimentos acerca da realidade, posto que esta é historicamente construída, enfatizando a importância de se estimular as atividades grupais (Vygotskty, 1989).

0 brinquedo é o reino da espontaneidade e liberdade, de forma que satisfazer às regras torna-se, para a criança, fonte de prazer. Assim, as maiores aquisições da criança são conseguidas por intermédio do brinquedo e do brincar. Por outro lado, ela se desenvolve a partir da experiência social estabelecida com o mundo exterior, sendo que brincar é uma forma de introduzi-la neste mundo e, visto como uma atividade social, propicia sua interação com a realidade. Garantindo-se a oportunidade para brincar, garante-se também a possibilidade de um desenvolvimento adequado (Madaleno, Pagan \&Assumpção, 1998; Poletto, 2005; Vygotsky, 1989). 
Ao se relacionar com determinados objetos, a criança cria uma situação imaginária, de extrema importância para o desenvolvimento do pensamento abstrato, e que será ferramenta para a formação do pensamento em outras etapas. No início da brincadeira, a criança se relaciona apenas com os objetos, mas depois sentiráa necessidade de se relacionar com outras crianças ou outros participantes em suas brincadeiras (Goldfeld, 2000).

As mães avaliaram a qualidade do relacionamento da criança com seus pares como "normal" em $55 \%$ das respostas, apontando brigas eventuais, enquanto em $45 \%$ das respostas não foram referidas brigas, mas apenas brincadeiras, confirmando a importância do exercício de brincar no desenvolvimento da confiança e capacidades em situações sociais, no julgamento das interações e no ser empático com os outros (Moyles, 2002).

Já no ambiente familiar, todas as mães avaliaram o relacionamento em casa como bom, demonstrando, em $30 \%$ das respostas, que brigas eventuais acontecem quando há discordância entre o casal. Elas procuraram enfatizar, durante as entrevistas, que evitam brigas na presença das crianças, por entenderem esta situação como desfavorável. Desse modo, proporcionam um ambiente doméstico com interações familiares mais positivas, que podem refletir em maior auto-estima, menos problemas de comportamento e mais recursos para as crianças lidarem com seus próprios fatores estressores (Calderon \& Greenberg, 1999), aspecto este também lembrado por Moyles (2002), ao defender o brincar em todas as idades, por prazer e diversão, levando a atitudes de aprendizagem em relação à vida.

As respostas também mostraram que as crianças têm uma ligeira preferência pelas mães (35\%) no relacionamento familiar, enquanto que em $35 \%$ dos casos, a procura está equilibrada entre pai e mãe. Durante a entrevista, foi possível observar que essa relação é construída, em geral, com o adulto que tem maior aceitação da deficiência, o que pode ser explicado em função de como os pais enfrentam o fato de terem uma criança com deficiência auditiva, afetando tanto 0 ajuste familiar quanto o resultado das intervençõescom a criança (Calderon \& Greenberg, 1999).

Todas as mães afirmaram gostar de brincar com os filhos, apesar de a maioria (70\%) relatar dificuldades nessa atividade, principalmente nos momentos em que as regras são necessárias, mencionando a impaciência da criança e/ou o fato de que ela quer fazer prevalecer sua vontade. A surdez deve ser compreendida como causadora de falha na comunicação e atraso na linguagem, o que leva a bloqueios de interação e a outras dificuldades, justificando as queixas dos pais em relação à agitação, impulsividade e impaciência, uma vez que as crianças não conseguem entender 0 contexto da situação, dificultando 0 alcance da adequação social. Os momentos de brincadeira da mãe com a criança favorecem a interação e levam à superação de tais dificuldades. Entretanto, sem orientação adequada, tais dificuldades podem aumentar (Goldfeld, 1997, 2000).

Pode ocorrer que as mães de crianças com deficiência auditiva apresentem padrões empobrecidos de interação com seus filhos, enfatizando mais os objetos do que as brincadeiras sociais, desprezand o seu importante papel em promover a compreensão da atividade ea motivação para o estabelecimento de uma comunicação efetiva e facilitadora do desenvolvimento da linguagem ( anjua et al. 2002; MacDonald \& Pien, 1982; MacTurk, Meadow-Orlans, Koester \& Spencer, 1993; Rossi, 2000). Daí a importância da orientação profissional.

Desta forma, a interação da mãe com a criança, em situação de brincar, pode favorecer a aprendizagem de posturas sociais, e as dificuldades ap resentadas, justificadas pela falha na comunicação, ilustram a necessidade dos treinos em habilidades sociais, passíveis de serem alcançados por meio das brincadeiras entre mães e filhos.

A forma de educar os filhos é crucial para a promoção da aceitação social (Bolsoni-Silva \&Maturano, 2002), sendo que a escassez dessa interação positiva ea falta de monitoramento e supervisão nas atividades das crianças são favorecedoras de comportamentos inadequados. Os resultados obtidos neste estudo demonstram que as mães procuravam, inicialmente, direcionar o comportamento da criança, explicando ou mostrando como esta deveria agir, e até monitorando suas atividades. Os comportamentos inadequados apresentados pelas crianças, como agitação e birra, dentre outros, eram, por sua vez, prováveis conseqüências das recorrentes frustrações causadas pela dificuldade na comunicação. 
Em 65\% dos casos, a escolha da mãe era bater para corrigir tais comportamentos, 0 que pode levar a uma reação agressiva por parte das crianças. A prática de bater para corrigir comportamentos é desaconselhada por alguns autores (Gomide, 2001), também porque a criança que apanha pode vir a acreditar que é merecedora dessa ação. Com esta auto-percepção, seus comportamentos inadequadose anti-sociais podem se tornar manifestos, além de 0 ato de bater não extinguir o comportamento inicial. Bater, além de ineficaz, é desnecessário, até porque, ao ser apresentada a modelos, a criança passa a ser capaz de discriminar a inadequação do comportamento e de modificá-lo, ajustando-se ao meio social (Amaral, Bravo \& Messias, 1996).

Pais que buscam soluções alternativas variadas estão oferecendo às suas crianças uma técnica apropriada para a resolução de problemas, enriquecendo a sua compreensão de causa e efeito e inibindo comportamentos impulsivos (Calderon \& Greenberg, 1999). Isto pode levar ao desenvolvimento de autocontrole, autoconfiança e menor dependência.

Deficits na competência social são resultantes de uma socialização que envolve privação da linguagem, desencorajamento da independência e da responsabilidade, e ausência de aprendizado incidental. As crianças com deficiência auditiva freqüentemente recebem explicações limitadas para seus sentimentos, papéis, ações e conseqüências de seus comportamentos, podendo apresentar mais problemas de auto-estima, assim como compreensão limitada das causas e significados de muitos eventos (Greenberg \& Kusche, 1993).

As mães entrevistadas revelaram que destinam cerca de uma hora por dia p ara as atividades de brincar, cuidar e ajudar nas tarefas escolares, e desenvolvem a estimulação ao longo do dia, seguindo as orientações recebidas dos profissionais de fonoaudiologia.

De acordo com as respostas, as crianças são estimuladas, tornando-se capazes, em $85 \%$ dos casos, de se comunicar com pessoas de fora da família para fazer pedidos, garantindo um aspecto importante da aprendizagem de uma das habilidades sociais relevantes para uma vida independente, de acordo com Del Prette e Del Prette (1999). Além disso, as crianças participam de atividades em casa, como guardar os próprios brinquedos (35\%), limpar (40\%), lavar a louça
(25\%) e arrumar a cama (15\%). Durante as entrevistas, foi possível notar que as mães incentivam as crianças em outras atividades práticas do dia-a-dia, tais como pequenas compras em supermercados, padarias e mercearias.

Treinamento em habilidades sociais compreende esforços educativos voltados para a socialização, que vão desde a capacidade de comunicar as próprias necessidades e sentimentos, até apresentar-se adequadamente em situações sociais, uma vez que qualquer comportamento esperado, incluindo gostar de outras pessoas, não ser egoísta, ou ser responsável, deve ser ensinado (Amaral et al. 1996; Del Prette $\&$ Del Prette, 2003; Marinho, 2001).

\section{Considerações Finais}

A criança precisa de modelos para aprender sobre os comportamentos aceitos socialmente, mas a dificuldade na comunicação impede que ela receba explicações precisas, coerentes e completas para desenvolver a percepção do que lhe é exigido. Por outro lado, a mãe, diante da dificuldade de comunicação, precisa de auxílio e orientação para exercer o papel de educadora e evitar atitudes equivocadas, que não auxiliam a aprendizagem. Foram observados condições e empenho para que o brincar aconteça na interação da mãe ouvinte com seu filho deficiente auditivo severo e/ou profundo, porém, os resultados deste estudo podem ser utilizados mais eficientemente no preparo das mães.

A interação com a mãe, durante a atividade de brincar, possibilita o desenvolvimento das habilidades sociais necessárias para a adequação da criança ao seu meio. Se essa interação for baseada em uma variedade de estímulos, e intrinsecamente motivadora para a criança, a eficiência do treinamento em habilidades sociais torna-se ainda maior.

0 estudo trouxe esclarecimentos para os profissionais da área, demonstrando a necessidade de informação e orientação para as mães atuarem com seus filhos, por exemplo, nas formas possíveis de comunicação, para que esta seja otimizada, visando que ambos alcancem melhores níveis de desenvolvimento e adequação social. 


\section{Referências}

Amaral, V. L. A. R., Bravo, M. C., \& Messias, T. S. C. (1996). Desenvolvimento de habilidades sociais em adolescentes portadores de deformidades faciais. EstudosdePsicologia (Campinas), 13 (3), 31-48.

Bolsoni-Silva, A. T., \& Maturano, E. M. (2002). Práticas educativas e problemas de comportamento: uma análise à luz das habilidades sociais. Estudos dePsicologia (Natal), 7 (2), 227-235

Calderon, R., \& Greenberg, M. T. (1999). Stress and coping in hearing mothers of children with hearing loss: factors affecting mother and child adjustment. AmericanAnnals of the Deaf, 144 (1), 7-18.

Cunha, N. H. S. (1994). Brinquedoteca: um mergulho no brincar. São Paulo: Maltese.

Del Prette, Z. A. P., \& Del Prette, A. (1999). Apsicologia das habilidades sociais: terapia e educação. Petró polis: Vozes.

Del Prette, Z. A. P., \& Del Prette, A. (2003). Habilidades sociais, desenvolvimento e aprendizagem: questões conceituais, de avaliação eintervenção. Campinas:Alínea

Goldfeld, M. (1997). A criança surda: a linguagem e cognição numa perspectiva sócio-interacionista. São Paulo: Plexus.

Goldfeld, M. (2000). O brincar na relação entre mães ouvintes e filhos surdos. Tese de doutorado não-publicada, Escola Paulista de Medicina, Universidade Federal de São Paulo.

Gomide, P. I. C. (2001). Efeitos das práticas educativas no desenvolvimento do comportamento anti-social. In M. L. Marinho \& V. E. Caballo. Psicologia clínica e da saúde (pp.33-53). Londrina: UEL.

Greenberg, M. T., \& Kusche, C. A. (1993). Promoting social and emotional development in deaf children: the PATHS project. Seattle: University of Washington.

Janjua, F., Woll, B., \& Kyle, J. (2002). Effects of parental style of interaction on language development in very young severe and profound deaf children. Internationaljoumal of Pediatric Otorhinolaryngology, 64 (3), 193-205.

Juarez, A. (1992). Intervenção fonoaudiológica da surdez infantil. In J. P. Casanova. Manual de fonoaudiologia (pp.190-211). Porto Alegre: Artes Médicas.

MacDonald, L., \& Pien, D. (1982). Mother conversational behavior as a function of interactional intent. Journal of Child Language, 9 (2), 337-358.
MacTurk, R. H., Meadow-OrlansK. P., Koester, L. S., \&Spencer, P. E. (1993). Social support, motivation, language, and interaction. A longitudinal study of mothers and deaf infants. American Annals of the Deaf, 138 (1), 19-25.

Madaleno, A., Pagan, L. H., \&Assumpção, F. B. (1998). Crianças com problemas psiquiátricos em programas de brinquedoteca: análise de um ano de atendimento. Revista dePsicopedagogia, 17 (44), 45-50.

Marinho, M. L. (2001). Subsídios ao terapeuta para análise e tratamento de problemas de comportamento em crianças: quebrando mitos. In M. L. Marinho, V. E. Caballo (Orgs.), Psicologia clínica e da saúde (pp.3-21). Londrina: UEL.

Motti, T. F. G. (2000). A rotina de um centro de referência em deficiência auditiva: perspectiva de pais e profissionais. Dissertação de mestrado não-publicada, Centro de Educação em Ciências Humanas, Universidade Federal de São Carlos.

Moyles, J. R. (2002). Só brincar? Porto Alegre: Artmed.

Peña, J. (1992). Dados de introdução à patologia e terapêutica da linguagem. In J. P. Casanova. Manual de fonoaudiologia (pp.1-15). Porto Alegre: Artes Médicas.

Poletto, R. C. (2005). A ludicidade da criança e sua relação com o contexto familiar. Psicologia em Estudo, 10 (1), 2005. Recuperado em novembro 28, 2006, disponível em http://www.scielo.br/scielo

Rossi, T. R. F. (2000). Brincaruma opção para vencero obstáculo da interação entre mãe ouvinte e filho surdo. Tese de doutorado não-publicada, Faculdade de Educação Física, Universidade de Campinas.

Santos, T. M. M., \& Russo, I. C. P. (1993).A prática da audiologia clínica. São Paulo: Cortez.

Silva, D. N. H. (2002). Como brincam as crianças surdas. São Paulo: Plexus.

Villas Boas, A. C., Rodrigues, O. P. R., \& Yamada, M. O. (2004). Um estudo da interação da díademãe-criança com implante coclear. Monografia de especialização em Psicologia Clínica não-publicada, Universidade de São Paulo, Bauru.

Vygotsky, L. S. (1989). A formação social da mente: 0 desenvolvimento dos processos psicológicos superiores. São Paulo: Martins Fontes.

Recebido em:29/9/2005

Versão final reapresentada em: 11/1/2007

Aprovado em: 13/2/2007 
